\title{
PRIMARY CARBIDES IN ALLOY 718
}

\author{
A.Mitchell \\ Dept of Materials Engineering \\ University of British Columbia \\ Vancouver BC Canada
}

\begin{abstract}
This study presents the effects of long term homogenisation at $1200 \mathrm{C}$ on the as-cast structure of alloy 718 in terms of the size distribution of the primary carbides. We find that the size distribution changes slightly over the first $20 \mathrm{~h}$ of treatment, following a solution of some of the carbide, but that it does not change significantly over the next $180 \mathrm{~h}$, indicating a rapid process of following the solution equilibrium at temperature. The effect is also reported in relation to the melting of an electrode of the same structure during the VAR process. It is found that the as-cast structure of the electrode used in VAR does not influence the structure of the VAR ingot in respect of primary carbide size distribution.
\end{abstract}

\section{Introduction}

The role of carbon in the metallurgy of alloy 718 is not completely clear. The strongest effect is that of the primary carbide ( $\mathrm{MC}$ - type, where $\mathrm{M}$ is principally $\mathrm{Nb}$, but can also contain Ti). Past reports $(1,2)$ have claimed the presence of secondary carbides (M7C3 or $\mathrm{M} 2 \mathrm{C}$ - type), which could play a part in pinning grain boundaries during heat treatment and also in some strengthening mechanisms, but their presence has not been subsequently substantiated. M6C has also been reported (3) in samples which have undergone longterm heat treatment, forming in small amounts at grain boundaries. Carbon is almost insoluble in the primary gamma phase of 718 and segregates strongly during solidification (4). As a result, although there are no carbides precipitated in the liquid above the liquidus temperature (1330C) (5) When the temperature falls to $1280 \mathrm{C}$, corresponding to approximately $50 \%$ solidification $(6,7,8)$, the carbon concentration in the remaining liquid rises to the point where the solubility product of $\mathrm{NbC}$ is exceeded and the precipitation of $\mathrm{NbC}$ therefore commences. This process is aided by the strong segregation of $\mathrm{Nb}$, which leads to an $\mathrm{Nb}$ concentration of $10 \mathrm{wt} \%$ at the point of $50 \%$ solidification (4). The solubility product of $\mathrm{NbC}$ has been computed (5) at this temperature on the basis of the assumed and measured segregation coefficients of $\mathrm{Nb}$ and C. The carbide precipitation continues during the remaining solidification. At the alloy solidus (1220C), the primary carbides usually contain a small amount of $\mathrm{Ti}$ in their peripheral regions. The final eutectic process depends on the solidification rate and on the precise composition of the alloy, but is basically the precipitation of a mixture of gamma and $\mathrm{NbC}$ with the addition of Laves phase under conditions of low solidification rate and high $\mathrm{Nb}$ concentration $(6,7)$. The distribution and size of the primary $\mathrm{NbC}$ particles is determined by this precipitation process and remains unchanged during the normal 
working and heat treatment applied to the alloy (9), although the eutectic carbide clusters may be elongated into stringers giving greater inter-particle separation. A mass balance calculation of the $\mathrm{Nb}$ and $\mathrm{C}$ concentration, based on metallographic determination of the primary $\mathrm{NbC}$ particle concentration lead to the conclusion (5) that in an alloy containing $0.03 \mathrm{wt} \% \mathrm{c}$ and $5.3 \mathrm{wt} \% \mathrm{Nb}, 12 \%$ of the carbon resides in the primary $\mathrm{NbC}: 64 \%$ of the carbon in eutectic $\mathrm{NbC}$ and the residual carbon is in solution in the gamma phase at that temperature, although the latter amount is presumed to be very small since no secondary carbides have been observed to be precipitated during cooling in the solid phase. This calculation, however, did not take account of any carbon contained in titanium carbonitrides which could account for much of the carbon content assigned to solution in gamma.

There are several reports of primary carbides going into solution at temperatures close to the liquidus in amounts sufficient to cause liquation cracking during welding $(10,11)$ or Ostwald ripening (12) of a fine $\mathrm{NbC}$ structure in a wrought product. The former reports state that the carbide size remains stable up to $1200 \mathrm{C}$ but that the partial melting of the eutectic region occurs at $1215 \mathrm{C}$, below the normally-accepted liquidus temperature of 1220C. The alloy compositions used in this study (10) were at low Nb content $(4.70-5.0$ $\mathrm{wt} \%$ ) and the effect would be more pronounced at the higher values used in PQ 718 for the highest strength applications. The effect of Ostwald ripening of fine carbide clusters (presumably originating in the eutectic precipitation) in a wrought structure is reported (12) at temperatures above $1177 \mathrm{C}$, with incipient melting at temperatures above $1191 \mathrm{C}$.

The mechanical properties of 718 have been the subject of very extensive studies. One conclusion of these works is that the dynamic properties (LCF, stress rupture etc) are very sensitive to the presence of non-metallic inclusions in the size range above approximately 20 microns. Below that size range, the effect of the non-metallic inclusions becomes submerged in the general microstructural features consisting of primary carbides and the various morphological variations of the delta phase precipitates. At a given grain size, the predominant LCF control factor in clean 718 appears to be the size distribution of the primary carbides, particularly if they occur in stringers and with added TiN particles. It is of interest therefore to question the role of carbon in 718 particularly as it applies to the formation of $\mathrm{NbC}$. Alloys having very low carbon content have been examined. Ruiz et al (13) refer to reports showing no adverse effects in stress rupture properties at carbon levels down to $0.006 \mathrm{wt} \%$ : Banik et al (14), however, report reduced stress rupture properties at the same carbon level. Both of these carbon contents are below the level at which any primary carbide would be precipitated during solidification (15) and any positive or negative effects would be associated with the way in which the eutectic carbide had been dispersed by mechanical working and/or heat treatment. The details of these processes are not given in the reports.

A potentially-complicating factor in the interpretation of the above observations lies in the content of TiN particles. The solubility limit of $\mathrm{TiN}$ in 718 at the liquidus temperature is $28 \mathrm{ppm}$ (15), which implies that in the normal nitrogen content range of the alloy much of the nitrogen is in the form of solid TiN particles at that temperature. TiN and $\mathrm{NbC}$ are isomorphous and hence the TiN acts as the principal nucleating site for the 
precipitation of primary carbide. It has been noted that in alloys with very low nitrogen content, the precipitation of primary carbide is delayed until close to the solidus temperature when the segregation has driven the $\mathrm{C}$ and $\mathrm{Nb}$ contents to a level enabling nucleation on particles other than TiN. In such alloy composition the extent of eutectic precipitation is enhanced and there is also a higher level of eutectic Laves phase present at the end of solidification (16). The nitrogen levels required to produce this effect are less than 5ppm (the solubility product of TiN at the solidus temperature) and are hence not encountered in commercial production of 718. The carbide nucleation on TiN gives a composite particle with a core of TiN and hence has been generally described as "carbonitride" in commercial alloy structures. It has been noted (15) that all large primary carbides have such a structure.

The purpose of the present study is to demonstrate the effect of high temperature homogenization on the carbide distribution found in as-cast 718 ingots with a view to better understanding the effects on it of homogenization time and temperature.

\section{Experimental}

Samples were cut from a section of the mid-radius position of a $450 \mathrm{~mm}$ diameter ESR ingot of IN718 which had not been subjected to any heat treatment beyond the normal cooling process following the ESR mold stripping. The alloy composition contained $0.025 \mathrm{wt} \%$ carbon, $5.3 \mathrm{wt} \% \mathrm{Nb}$ and $60 \mathrm{ppm} \mathrm{N}$. The samples were in the form of $20 \mathrm{~mm}$ cubes. The structure was revealed by polishing and etching and the primary carbide size distribution determined microscopically by measuring the maximum linear dimension of the 5 largest carbides in 40 separate fields. The primary carbides were taken to be those not associated with the eutectic structure.

Samples were wrapped in molybdenum foil and sealed under vacuum in silica tubes. The tubes were then inserted into a furnace held at 1200C for a given length of time and then air cooled. After the heat treatment the samples were examined metallographically as above. The carbide sizes found are given in Table 1 and the liquated eutectic structure observed is shown in Fig 1.

A second examination was carried out in which the melting tip of a VAR electrode (taken from an industrial melt which was terminated without hot-topping) was sectioned. The alloy composition was the same as that found for the ESR ingot. The carbide structure was determined as above. The result is shown in Fig 2.

\section{Discussion}

Homogenisation:

The carbide size range for the as-cast sample is consistent with the computed solidification times at the mid-radius position for the melting conditions applied to the ESR ingot $(17,18)$. After $20 \mathrm{~h}$ heat treatment at $1200 \mathrm{C}$ the carbide size has decreased slightly, consistent with a small solution of the carbide particles as the solubility product adjusts to the temperature of $1200 \mathrm{C}$. After treatment at $1200 \mathrm{C}$ for $200 \mathrm{~h}$, the carbide size 
does not change, indicating that the particles are in equilibrium at that temperature and that the amount of Ostwald ripening is too small to be detected. This observation is not in conflict with the findings of Poole (12) since the starting structure for the heat treatment in that case was one in which the carbides had been dispersed by mechanical working and the content of smaller particles was much higher than in the present samples. It is, however, clear from the present work that there is sufficient solubility of $\mathrm{NbC}$ at $1200 \mathrm{C}$ that a diffusional process would be fast, as was found in the experimental work of Poole (12).

The structures observed after $200 \mathrm{~h}$ treatment demonstrate a significant degree of eutectic liquation and carbide melting as was found for structures in the heat-affected zone of welds (11) and also by Radhakrishnan (10). This result underlines the hazard of taking the ingot homogenization temperature to $1200 \mathrm{C}$ in an effort to decrease the industrial homogenization process time.

Remelting Process:

The structure changes observed in the VAR electrode tip may be interpreted in a parallel manner to those discussed above. It is clear that the primary carbides dissolve during the remelting process to give a liquid film on the melting tip of the electrode which does not contain any solid carbides. The solution process is therefore fast, as was found also in the above process of carbide size re-arrangement upon heat treatment. The implication is that the carbide size distribution of the electrode does not affect the carbide distribution in the remelted ingot. The implications for the remelting processes are most relevant to the triple melt sequence of VIM/ESR/VAR. The carbide structure of the ESR ingot in a triple-melt process is hence completely eliminated during the subsequent VAR process and the carbide size distribution of the final VAR ingot is solely established by the freezing conditions of the final melt. In an ESR process which is to be used to prepare the electrode for subsequent VAR, the ESR melting conditions should therefore not contain any consideration of controlling the carbide structure, nor is there a need for homogenization of the ESR ingot before use as the VAR electrode although an appropriate level of heat treatment for stress relief is necessary. Similar considerations would also apply to the VIM cast ingot for use as an ESR electrode. Although not examined in the present work, it is highly likely that the same effects would also cause the elimination of any freckle or tree-ring segregation defects in the ESR ingot in respect of their influence on the structure of the final VAR ingot.

The examination of the VAR electrode tip also showed that the above reasoning does not apply to TiN. The alloy under study contained 60ppm $\mathrm{N}$ and hence 32ppm was in the form of solid TiN particles at the liquidus temperature. The size distribution of the TiN remains essentially constant through the melting process indicating a slow approach to equilibrium and only a minor amount of solution before the alloy forms the liquid film on the melting tip. This finding supports the view that the nitride particle distribution in the electrode will form the basis for the distribution in the ingot and that many of the nitride particles found in the ingot will be the same particles as those in the electrode. In terms of triple melting of 718, part of the TiN distribution in the ESR ingot will then persist through the final VAR melt, the only modification being the physical removal of a 
fraction of the particles through the mechanism of surface flow on the ingot top surface (15) and the solution/re-precipitation mechanism of that fraction of TiN which went into solution during the residence of the alloy in the liquid phase. This finding underscores the need for control of the alloy nitrogen content at a level at or below the solubility limit of $\mathrm{TiN}$ at the liquidus throughout the triple melt sequence.

\section{Conclusions}

This study has two principal conclusions. First, long-time homogenization at temperatures at or above $1200 \mathrm{C}$ is detrimental to the structure of either ingot or forged product 718. Second, the carbide structure of the ESR ingot in triple melting does not influence the carbide structure of the subsequent VAR ingot, but that the nitride distribution of the ESR ingot can influence the nitride distribution in the subsequent VAR ingot.

\section{Acknowledgments}

The author was greatly assisted in the experimental work in this study by Dr A Ahktar and Mr D Breband. The author is also grateful for the assistance of the Carpenter Technology Corp in provision of experimental material.

\section{References}

1. M Kaufman and A E Paltry; "Phase Structure of Inconel 718 and 702 Alloys", Trans AIME, 1961, 221, pp $1253-1262$.

2. J F Barker; "Inconel 718 Phase Study Review", DM 61-183, General Electric Company, July 6 1961; cited in "Physical Metallurgy of Alloy 718", DMIC Report 217, June 11965.

3. D D Keiser and H L Brown: "A Review of the Physical Metallurgy of Alloy 718"; Report ANCR-1292 UC-25, Feb 1976, Idaho National Laboratory.

4. P Auburtin, S L Cockcroft, A Mitchell, A J Schmalz; "Centre Segregation, Freckles and Development Directions" "Superalloys 718, 625, 706 and Derivatives" ed. E Loria, publ. Minerals, etals and Materials Soc. New York 1997, pp 47 - 54.

5. A Mitchell, S L Cockcroft, C Schvezov and A J Schmalz: "Precipitation of Carbides in Inconel 718", "Superalloys 718625706 and Derivatives", ed E Loria, publ. Metals Minerals and Materials Society, New York, 1994, pp 116 - 124.

6. T Antonsson, H Frederiksson: "The Effect of Cooling Rate on the Solidification of Inconel 718”, Met Trans B, 2005, 36B, pp $85-101$.

7. G A Knorovsky, M J Cieslak, T J Headley, A D Romig Jr, W F Hammeter: "Inconel 718; A Solidification Diagram", Met Trans A, 1989, 20A, pp 2149-2158. 
8. C A Matlock, J M Merrill, B C Ambrose, R C Wilcox and R A Overfelt: "Solidification Map of Directionally Solidified Inconel 718" J Microstructural Science, 1994, 21, pp51 - 60 .

9. Amida Oradei-Basile and J F Radavich; “A Current T_T_T Diagram for Wrought Alloy 718"; "Superalloys 718, 625, 706 and Derivatives" ed E Loria, publ Metals minerals and Materials Soc, New York 1991, pp 325 - 335.

10. H Radhakrishnan and R G Thompson: "A Phase Diagram Approach to Study Liquation Cracking in Alloy 718', Met Trans A, 22A, pp 887 - 901.

11. R G Thompson; "Microfissuring of Alloy 718 in the Weld Heat-Affected Zone", J Metals June 1988, pp $44-48$.

12. J M Poole, K R Stultz and J M Manning: "The Effect of Ingot Homogenisation Practice on the Properties of Wrought Alloy 718 and Structure", "Superalloy 718 Metallurgy and Applications" ed E Loria, Metals Minerals and Materials Soc New York 1989, pp $219-240$.

13. C N Ruiz, S S Mysore, L A Jackman, R B Lal and A A Wereszczak: "Creep Behaviour of Fine Grain, Low Carbon Allvac 718”, "Superalloys 718, 625, 706 and Derivatives” ed E Loria, publ Metals Minerals Materials Soc New York 1994, pp 523 $-533$.

14. T Banik, P W Keefe, G E Maurer and L Petzold; "Ultra Fine Grain Low Carbon 718", "Superalloys 718 625, 706 and Derivatives" ed E Loria, publ Metals Minerals and Materials Soc New York, 1991 pp 383 - 396.

15. A Mitchell; "Precipitation of Primaty Carbides in Alloy 718" "Superalloys 718, 625, 706 and Derivatives" ed E Loria, publ Metals Minerals Materials Soc, New York 2005, pp $73-83$.

16. E.C.Young and A. Mitchell; "Some Aspects of Nitrogen Addition and Removal during Special Melting and Processing of Iron and Nickel-Base Alloys" J High Temperature Materials and Process, 2001, 20 (2), p79 - 101.

17. K M Kelkar, J Mok, S V Patankar and A Mitchell; "Computational Modeling of Electroslag Remelting Process”, J Phys IV France, 120, p.421-428, 2004.

18. A. Mitchell: "Influence of Process Parameters during secondary melting of nickelbase superalloys" J Materials Science and Technology, 25 (2) p.112 - 118, 2009. 
Table 1 Primary Carbide Size Distribution, based on the maximum linear section length of the 5 largest particles in 40 areas.

\begin{tabular}{|c|c|c|}
\hline Time $(\mathrm{h})$ & Temperature & Carbide size (microns) \\
\hline As-cast & $1200 \mathrm{C}$ & $12.5+/-2$ \\
\hline $20 \mathrm{~h}$ & $1200 \mathrm{C}$ & $10.8+/-2$ \\
\hline $200 \mathrm{~h}$ & $1200 \mathrm{C}$ & $11+/-2$ \\
\hline
\end{tabular}

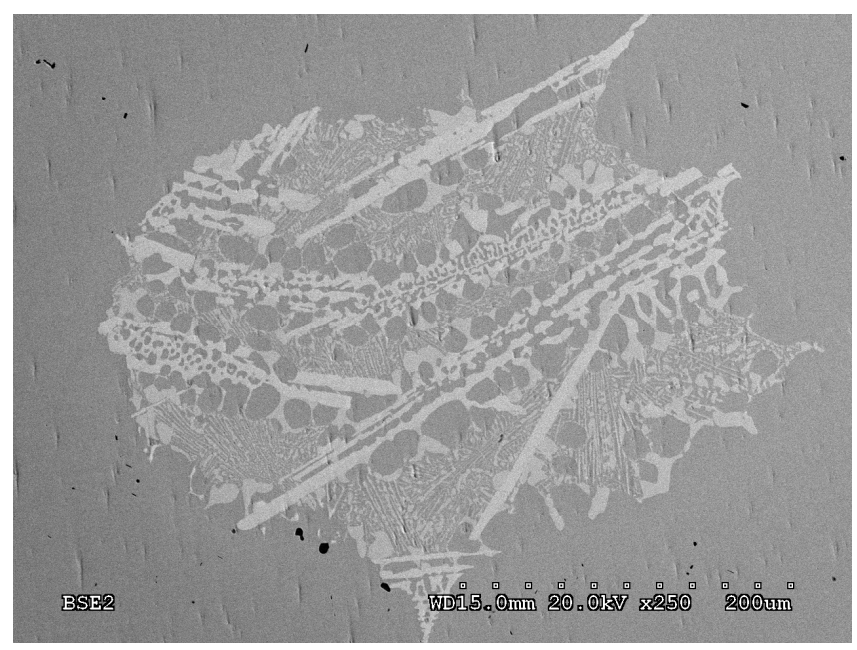

Fig 1; Structure of the liquated primary grain boundary after 200h at 1200C, x100

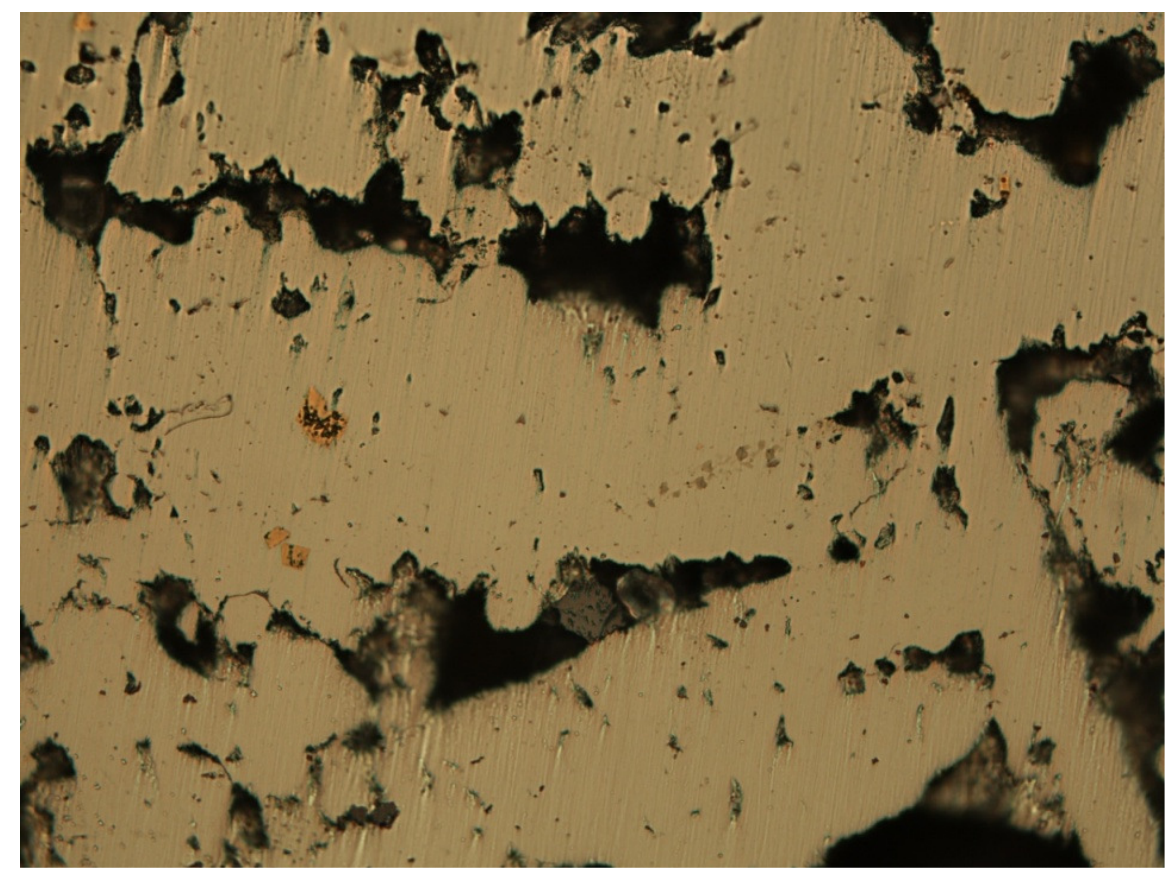

Fig 2; Liquid film on the VAR electrode tip, x 50. Large nitrides may be seen but the carbides have almost entirely dissolved. The dark areas are porosity resulting from the rapid solidification of the liquid film after "power off". 